about 100 miles east of the ancient Maya city of Chichen Itzá, and has the largest assemblage of buildings, with the exception of Tikal, in the Maya area, is one of the few sites of which the ancient name is still known to present-day Indians. Vestiges of ancient cult and ritual still linger on before its stelæ; while the deities of Cobá are venerated in bee-keeping and first-fruit ceremonies in distant villages, where the inhabitants assuredly have no knowledge of the present-day ruins of Cobá.

The site of Cobá was especially favourable for Maya colonisation, owing to the propinquity of an ample supply of surface water in a chain of lakes, and a plentiful rainfall, which fostered the growth of vegetation and the pursuit of agriculture.

The area which has been mapped up to the present covers $9 \mathrm{~km}$. from north to south and $5 \mathrm{~km}$. from east to west.

To the south the ground is still unexplored, and more ruins may yet be found there. Of the surveyed area, the northern part is literally covered by ruins. Between the main groups of Cobá and Nohoch Mul there is an almost unbroken succession of mounds, culminating in a group of considerable importance associated with Nohoch Mul. The shores of Lakes Cobá, Macanxoc, and Sacakal are surrounded by mounds which, excluding those of the last-named lake, form one great site, $3.5 \mathrm{~km}$. by $2 \mathrm{~km}$.- certainly one of the largest in the Maya area.

One of the most striking features of Cobá is the network of artificially constructed raised roads connecting the various groups about the lakes and running off in all directions to distant sites. One of these leads to Yaxuná, a distance of $100 \mathrm{~km}$., terminating only $20 \mathrm{~km}$. from Chichen Itzá. These roads are raised above ground-level and, for the most part, run perfectly straight. They are built of vertical slabs of roughly dressed stone, with an inside fill of large stone, covered with smaller stone. A fine plaster surface has now weathered away.

Broadly speaking, the ruins of the Cobá district fall into two classes of construction, a superior and an inferior, which, while not differing radically, exhibit certain variations in quality of workmanship and design. A preponderance of the buildings shows a closely connected court type of assemblage with a fixed scheme of orientated groups. The Macanxoc groups, however, abandon the orientation. Such compact assemblage finds its most common expression in the Peten rogion of Guatemala at Tikal, Nahum, and similar sites; while Uaxactun shows a tendency to separate groups, though still with an orderly scheme of arrangement of buildings, definitely related to one another. Notwithstanding the difficulty of drawing parallels between Cobá and other areas, there are certain distinctly marked affinities with the 'Old Empire' centres to the south, which is borne out by the analysis of the art of Macanxoc, for which Mr. Jean Charlot has been responsible. At the same time, there is sufficient evidence of independence in development, especially in the unique character of the complicated system of artificially made roads, to suggest a long period of growth locally, and even possibly several occupations.

At one time or another, no less than fifty monuments have been discovered at Cobá. Of these, twenty-four are carved, twenty-three being stelæ and one an altar. The stelæ at Cobá and Macanxoc are placed in 'shrines'-stone structures consisting of a platform with back walls and short projecting side walls. Structures of this type have not been reported from any other Mayan site. It is possible that they were roofed over with thatch.

Some of the stelæ are dated in the Maya notation. Of these, the earliest is of some importance in its bearing on the spread of Maya colonisation into northern Yucatan. Hitherto it has been held, on the authority of a statement in the Book of Chilam Balam, that Chichen Itzá marks the first Maya intrusion into the area. This is dated at an equivalent in the Christian system of A.D. 452 ; but a dated monument at Cobá gives a date equivalent to A.D. 353 , making this site at least a hundred years earlier; while the evidence of the development of style in architecture and art suggests that the original settlement was considerably older. A series of dates is now known from the three cities of Tuluum, Ichpaatun, and Cobá, ranging from A.D. 314 to 353 , which points to a movement along the east coast of Yucatan, of which the terminal was Cobá, and the place from which it originated in the ' Old Empire' area of Peten, possibly at Naranjo, though on the evidence of affinities in art, Mr.J. Charlot thinks it possible that the site of origin may still await discovery.

\title{
Sunspots, Planets, and Weather
}

ONE of the most interesting problems of meteorology is the relation between sunspots and terrestrial weather. In most parts of the world, including the British Isles, the relation is too complex to be readily demonstrable, and the number of unknown factors too great for it to be of use in forecasting, but in a few areas, for one reason or another, the control by sunspots becomes dominant. Mr. Inigo Jones, Director of the Bureau of Seasonal Forecasting in Queensland, believes that Australia is one of these areas under solar control, and in a recent presidential address to the Queensland Astronomical Society* he quotes a number of examples.

Mr. Inigo Jones carries the problem a stage further, however, seeking beyond sunspots for their causes. The sunspot cycle, striking as it is, is not perfectly regular, and the dates of maxima and minima cannot be forecast exactly. He believes that this cycle is caused by the movements of the planets; it is dominated by Jupiter, which has a periodicity of 11.86 years, but irregularities are caused by Saturn and to a less extent by Uranus and Neptune, and these introduce additional cycles which reduce the average

* "Seasonal Forecasting." Brisbane, 1931.

No. 3270 , VoL. 130$]$ length to $11 \cdot 1$ years. Hence he seeks for the explanation of abnormal weather not only in the sunspots themselves but also in the conjunctions of the planets. Especially important is the conjunction of all four, which occurs at intervals of 164 years and is often associated with world-wide climatic disturbance and severe famines.

The way in which sunspots operate is still a mystery, but there are many indications that the greatest effects take place high in the atmosphere, in the ozone layer, the conducting layers, and the auroral zone, and the surface effects may be of a secondary nature only. Mr. Inigo Jones describes a possible mechanism as follows : "Cyclones to which our heaviest rains are attributable are caused by discontinuities between air masses having different temperature and moisture contents, and it is clear that any upper air changes must accelerate such differences, and further, the fact that sunspots by their emanations disturb the upper air and so suddenly intensify these differences, shows easily how it is that the effect is produced, and at the initiatory or terminal stage of each sunspot's visibility". More prolonged effects may take place through the action of ozone, and investigations which 
are now being made into the relations between solar radiation and ozone should throw a great deal of light on the effect of sunspots on weather.

The problem is complicated by terrestrial effects, such as the lag in changes of world temperature caused by the masses of polar ice and by the movements of powerful ocean currents, or the disturbing effects of great volcanic eruptions. All these factors will need to be taken into account before long-range forecasts can attain a really effective precision, but $\mathrm{Mr}$. Inigo Jones gives a number of examples to support his view that in Australia at least the major control of weather is exerted by the sun.

\section{Canned Fruit and Vegetables}

THE processes that made the preservation of fruit 1 and vegetables possible were discovered in France more than a century ago, but although numerous canning factories have been in operation in several European countries, America, and parts of the British Empire, it is only during the last ten years that any have been built in England. However, 53 such factories were in operation in this country by 1931 .

The quantity of canned fruit imported into England has shown an enormous increase in recent years. In view of this greater demand, the home industry has every prospect of success, provided the grower will produce the right type of fruit and vegetable. To meet this need, the Ministry of Agriculture has published an illustrated bulletin (No. 45) entitled

"Fruit and Vegetable Production for Commercial Canning" (London : H.M. Stationery Office, 1s. 3d.).

Plums are by far the most important tree fruit for canning purposes, the use of cherries being somewhat restricted owing to the tendency of the juice to act on the metal container and the difficulty of finding a suitable variety. As regards the commonly grown soft fruits, the majority may be successfully canned if firm, clean fruit is selected. Up to the present, peas are the only vegetable that has been canned in any quantity, but the possibilities of extending the industry to include other vegetables are indicated.

Production for the cannery is an entirely different proposition from production for the fresh market, and it is essential that the grower should recognise this from the start. On the whole, it would seem most suited to large-scale producers with mechanical methods of cultivation, as regular, standardised consignments are required and costs must be kept as low as possible. From the long experience obtained in other countries, the desirability of contract growing is indicated. Various methods of this system are discussed, but it is evident that special arrangements will need to be worked out to meet the particular requirements of the different erops. Some such methods should, however, do much to promote the development of the industry and give confidence to the growers.

\section{Standardised Preparations of Vitamins $A$ and $D$}

W

$\mathrm{E}$ are glad to note that British manufacturers have taken full advantage of the recent striking advances in our knowledge of the fat-soluble vitamins $\mathrm{A}$ and $\mathrm{D}$ and have now available for general clinical use standardised preparations of these highly important substances. The isolation of calciferol (vitamin D) by Dr. Bourdillon and his collaborators has been followed in a remarkably short space of time by its preparation on a commercial basis by British Drug Houses, Ltd., who are to be congratulated on the rapidity with which they have translated a delicate laboratory process to a works' scale. This firm now supplies, under the name of Radiostol Solution and Radiostol Pellets, pure crystalline vitamin D. The solution, the activity of which is such that one fluid ounce is equivalent to fifty fluid ounces of cod-liver oil, is a tasteless preparation of the pure vitamin in oil, while the pellets contain it incorporated in cocoa butter, one pellet being equivalent to a full adult dose of cod-liver oil.

Another physiologically standardised vitamin D product, sold under the brand name of Ostelin, emanates from the Glaxo Laboratories (Joseph Nathan and Co., Ltd.). This preparation, which was originally manufactured in 1924 from cod-liver oil but is now prepared by the carefully controlled irradiation of ergosterol, is also supplied in both liquid and tablet forms. Ostelin liquid, which is standardised to contain 5000 international units of vitamin $D$ per c.e., is tasteless and miscible with water, and can therefore be dispensed in pharmaceutical mixtures. The tablets contain, in addition to 500 units of vitamin D each, neutral calcium glycerophosphate.

More recently the Glaxo Laboratories have also put on the market, under the brand name of Adexolin, a mixed preparation of both vitamins $A$ and $D$ in proportions normal to cod-liver oil. Adexolin is available both as liquid and capsules. The special feature of the liquid, a fluid oz. of which is equivalent in both vitamins to 20 fluid oz. of good cod-liver oil, is that as a result of a special process it is largely free from the objectionable taste of ordinary fish-liver oil concentrates. The capsules have been designed to allow the administration of larger quantities of the two vitamins than is necessary for infants. The prophylactic dose for adults is usually 1-3 capsules per day, but in cases of acute septicæmia complicated by high febrile conditions, so many as 24 capsules per day can, we are informed, be administered with highly favourable results.

\section{University and Educational Intelligence}

BIrmingham.- The degree of D.Sc. has been awarded to T. L. Ibbs for various papers on thermal diffusion and the form and field of force of the carbon dioxide molecule and allied subjects.

LoNDon.-Mr. J. L. S. Hatton, principal of East London College, has been elected vice-chancellor for 1932-33 in succession to Dr. J. Scott Lidgett, whose term of office expires on Aug. 31. Dr. W. R. Halliday, principal of King's College, has been appointed deputy vice-chancellor for the same period in succession to Canon Douglas.

Prof. D. T. Harris, since 1921 assistant professor in the Institute of Physiology at University College, has been appointed professor of physiology (London Hospital Medical College) as from Oct. I.

The title of University reader has been conferred on Dr. Evelyn E. Hewer, lecturer in histology at the London (R.F.H.) School of Medicine for Women.

OXFORD.-Among the honorary degrees conferred on June 22 were the following: D.Sc. on Sir John Russell, director of the Rothamsted Experimental Station, and Prof. Willem de Sitter, professor of astronomy in the University of Leyden; D.C.L. on Sir Arthur Salter, recently director of the Economic and Finance Section of the League of Nations.

Sir James Frazer is to deliver the Sir Basil Zaharoff lecture for this year.

THe National University of Ireland is about to enter upon its twenty-fifth year and has signalised the approach of this anniversary and "the special signific- 